\title{
Lung Adenocarcinoma with Metachronous Ovarian Metastasis: a long survival case report
}

\author{
Shuyang Yao ${ }^{1}$, Leiming Wang ${ }^{2}$, Xiaoru Tian ${ }^{1}$ and Yi Zhang ${ }^{1 *}$ (D)
}

\begin{abstract} clinicopathological features and treatment strategies remain unknown.

\section{Introduction}

Compared with common metastases like bone, brain, liver, adrenal glands and so on, lung cancer metastasis to uncommon sites occurs in less than $5 \%$ of cases, especially associated with a worse outcome, and the incidence of metastatic adenocarcinoma to the ovaries is only $0.07 \%$ [1]. This frequency, however, is increasing due to the rising incidence of lung adenocarcinoma in women and the prolonged survival time of lung cancer. Because of the paucity of reported cases $[2,3]$, the clinicopathological features and treatment strategies of these tumors remain unknown. Here, we report a long surviving patient with ovarian metastasis from lung adenocarcinoma.
\end{abstract}

Background: Lung adenocarcinoma which invades ovaries is very rare. However, with the increase of long-survival female lung cancer, more patients will suffer ovarian metastasis. On grounds of the paucity of reported cases, the

Case presentation: This patient was stage IV lung adenocarcinoma at first diagnosis. Following multiple-line systemic treatments, she experienced extensive pelvic metastasis. After debulking surgery and reevaluation about the drive genes, she was administered by targeted therapy. Up to now, the patient has shown no evidence of progression for 8 years after the initial diagnosis of primary lung cancer and 46 months after her ovarian metastasis.

Conclusion: The comprehensive treatment modality for the bilateral ovarian metastasis is effective in clinical course. Keywords: Lung adenocarcinoma, Ovarian metastasis, Debulking surgery, Targeted therapy, Case report

\section{Case presentation}

A 60-year-old woman presented with cough and dyspnea in March 2012. Computed tomography (CT) scans showed a left lower lobe mass, as well as plural metastasis

\footnotetext{
*Correspondence: steven9130@126.com

${ }^{1}$ Department of Thoracic Surgery, Xuanwu Hospital, The Capital Medical University, Beijing, China

Full list of author information is available at the end of the article
}

and pleural effusion. A pathological diagnosis of adenocarcinoma was performed by pleural biopsy. Lung tumor tissue was wild-type of epidermal growth factor receptor (EGFR) by the method of real-time polymerase chain reaction. Then she received two-line chemotherapies (docetaxel $\left(75 \mathrm{mg} / \mathrm{m}^{2}\right)+$ carboplatin $(4$ area under the curve $) \times 6$ cycles and pemetrexed $\left(500 \mathrm{mg} / \mathrm{m}^{2}\right)+$ cisplatin $\left(60 \mathrm{mg} / \mathrm{m}^{2}\right) \times 6$ cycles, respectively) with the best response of stable disease (SD) for each regimen, but it finally failed for progressive disease (PD) with new metastasis in bones and brain. Gefitinib had been administrated as her third-line treatment since July 2014.

In June 2016, she was admitted with the complaint of abdominal discomfort and obvious weight loss. CT scans of the ovarian tumor revealed the admixture of enhanced solid components and cysts, left $4.6 \times 3.5 \mathrm{~cm}$, right 2 . $6 \times 2.9 \mathrm{~cm}$, with extensive peritoneal thickening and massive ascites. Then, she underwent tumor debulking surgery. The tumor invaded not only bilateral ovaries, but also peritoneum, bladder, uterine. Even a great many of small nodules scattered on the surface of intestinal tubes. The following procedures were done: bilateral 
salpingooophorectomy, partial omentectomy, and peritoneal washings with cisplatin $80 \mathrm{mg}$.

Pathology showed a moderately differentiated papillary adenocarcinoma in ovarian. The tumor cells were arranged into glandular tubular and papillary structures with apical snouts and huge, hyperchromatic nuclei (Fig. 1a, b). Mucous epithelium could be seen in some areas with stromal fibrous proliferation. Tumor cells were immunopositive for thyroid transcription factor 1 (TTF-1), Napsin-A and cytokeratin (CK)-7 (Fig. 2a-c), and negative for paired box 8 (PAX-8), estrogen receptors (ER), progesterone receptor (PR) and CK20. Combined with the initial results of pleural biopsy (Fig. 1c, d), the diagnosis of ovarian metastasis from lung adenocarcinoma was established.
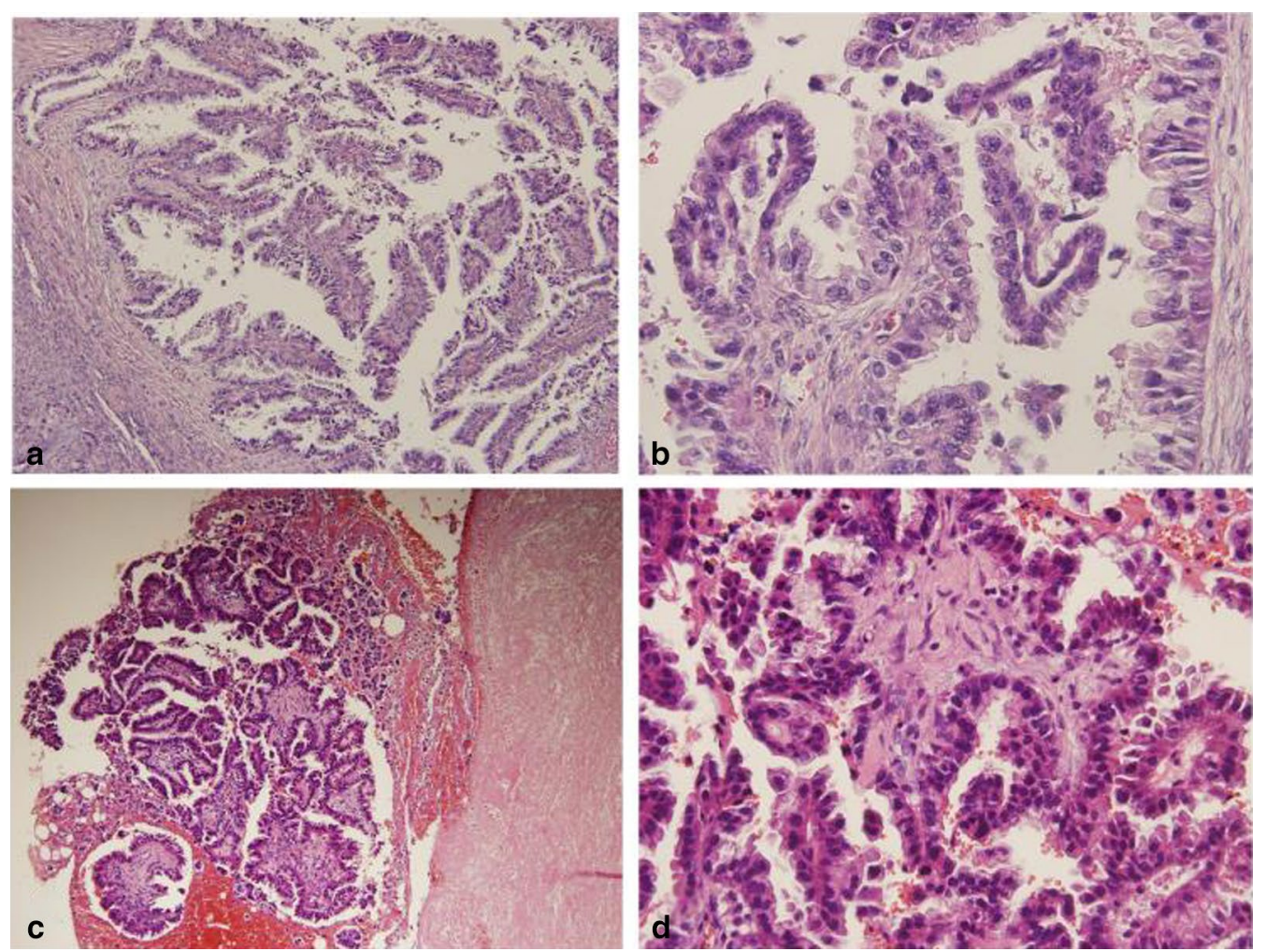

Fig. 1 In 2006, from debulking surgery, tumor cells are arranged into glandular tubular and papillary structures with apical snouts and huge, hyperchromatic nuclei. a H\&E, $\times 100 ; \mathbf{b} H \& E, \times 400$; In 2002, from pleural biopsy, tumor cells are arranged into glandular tubular and papillary structures with apical snouts and huge, hyperchromatic nuclei. a H\&E, $\times 100 ; \mathbf{b} \mathrm{H} \& \mathrm{E}, \times 400$
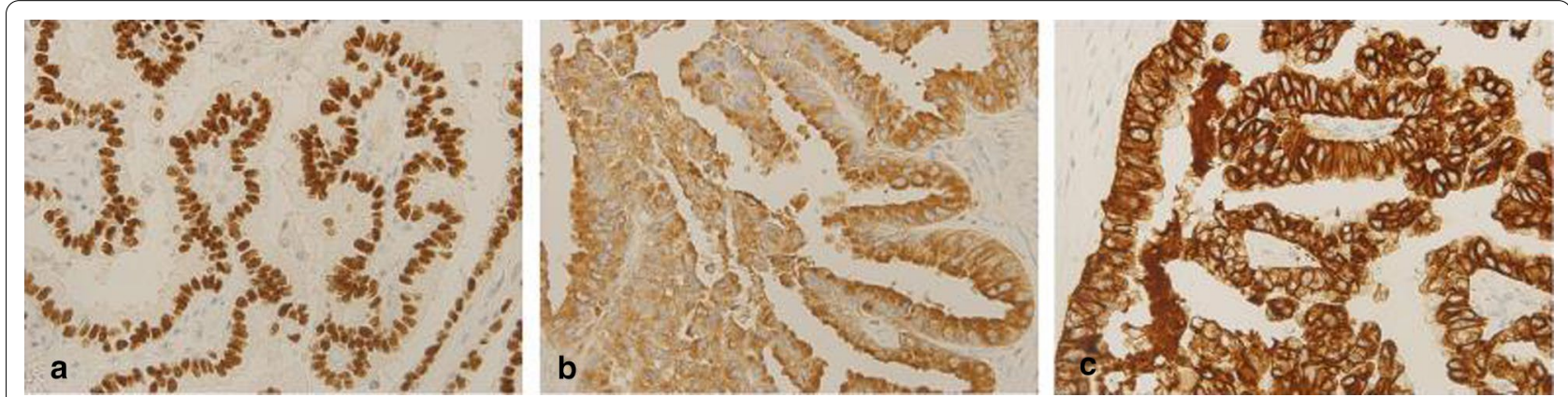

Fig. 2 In tissue from the ovarian debulking surgery, a tumor cells are immunopositive for TTF1. IHC, $\times 400$; $\mathbf{b}$ Tumor cells are immunopositive for NapsinA. IHC, ×400; c Tumor cells are immunopositive for CK7. IHC, ×400 
Evaluated by the testing method as before, it showed EGFR T790M mutation in exon 20. Then the patient received oral administration of osimertinib (80 mg once a day). Up to now, the patient has shown no evidence of progression on regular follow-up for 8 years after the initial diagnosis of primary lung cancer and 46 months after her ovarian metastasis.

\section{Discussion and conclusions}

Metastatic ovarian tumors account for $4.2 \%$ of malignant ovarian tumors [4], and $60-80 \%$ ofthe gastrointestinal tractmors oriasnate from gastrointestinal tra, $\mathrm{t}$ (named as Krukenberg tumor) and breast [5, 6]. Depended on CT and magnetic resonance imaging (MRI) findings of ovarian tumors, as it was observed in our case, the masses generally have no distinguished characteristics which contribute to make the judgement about the primary site. Therefore, differentiating between primary ovarian and metastatic adenocarcinoma is crucial since the treatment strategies and prognosis for these diseases are markedly different.

Traditionally, systemic therapy is recommended as the standard therapy for metastatic lung cancer. More remarkably, positive status of driving genes like anaplastic lymphoma kinase (ALK) rearrangement and EGFR mutation in lung cancer with ovarian metastasis has dramatically been reported [7-11] in the latest decade and low toxic targeted therapy would prolong the patients' lives. For the metastatic lung cancer patients, especially who have received multiple-line treatments, one problem appeared whether it is necessary to perform surgery debulking for accurate diagnosis.

Sufficiently resected tissue from cytoreductive surgery is needed owing to differential diagnosis between primary and metastatic ovarian tumors, as well as an accurate gene detection for afterwards appropriate regimen. Lung cancer is a heterogeneous tumor and many studies have reported the discrepancy of EGFR mutation status between the primary tumor and metastatic lesions from the same patient [12]. Like this case, the previous EGFR status of the primary tumor was totally different with the ovarian metastasis. On the one hand, insufficient tissue quantity or unsatisfied tissue quality might cause the first-time gene result not to present the real gene status. On the other hand, it took long time to possibly develop into various features in different metastatic sites. Whatever, updated driven genes testing of the newly progressive tumor is crucially warranted.

In theory, fewer cancer cells at the start of systemic treatment lead to a higher likelihood of cure, in part due to dose intensity of chemotherapy. Otherwise, it is helpful to make the residual cancer cell clones homogeneous, improving the sensitivity to the afterwards chemotherapies or targeted therapies. Based on studies which have reported the effectiveness of maximal tumor debulking surgery in lengthening the overall survival time compared to the absence of such surgical treatment in Krukenberg tumor [13], the debulking surgery may be a good choice for lung cancer patients with ovarian metastasis.

In conclusion, for the increasing incidence of lung cancer in females and improved survival time, physicians must keep in mind the possibility of ovarian metastasis in clinical course. Debulking surgery followed by optimal systemic treatment, especially targeted therapy may greatly contribute to the prognosis of lung cancer patients with ovarian metastasis. An additional case series will be necessary to confirm our results.

\section{Abbreviations \\ CT: computed tomography; EGFR: epidermal growth factor receptor; SD: stable disease; PD: progressive disease; TTF-1: thyroid transcription factor 1; CK: cytokeratin; PAX-8: paired box 8; ER: estrogen receptors; PR: progesterone receptor; MRI: magnetic resonance imaging; ALK: anaplastic lymphoma kinase. \\ Acknowledgements \\ We would like to thank Dr. Fu, Siqing from the university of Texas MD Ander- son cancer center for his critical review of the manuscript.}

\section{Authors' contributions}

SY was the chief oncologist in charge of the patient and completed the manuscript. LW was the pathologist of the patient and completed the pathologic part of the manuscript. XT reviewed the whole medical records which did the favor of the case report. YZ was the corresponding author who revised the manuscript critically. All authors have read and approved the manuscript.

\section{Funding}

Sailing Program Clinical Technology Innovation Project 2017 (XMLX201702).

The funding supported authors for the research and publication of this article.

Availability of data and material

The datasets used and/or analyzed during the current study available from the corresponding author on reasonable request.

\section{Declarations}

Ethics approval and consent to participate

This case was approved by the ethics committee of Xuanwu Hospital Capital Medical University.

\section{Consent for publication}

The patient signed informed consent for the publication of this case report and any associated images.

\section{Competing interests}

The authors declare that there are no conflicts of interest.

\section{Author details}

${ }^{1}$ Department of Thoracic Surgery, Xuanwu Hospital, The Capital Medical University, Beijing, China. ${ }^{2}$ Department of Pathology, Xuanwu Hospital, The Capital Medical University, Beijing, China. 
Received: 16 July 2020 Accepted: 8 February 2021

Published online: 14 April 2021

\section{References}

1. Niu FY, Zhou Q, Yang JJ, et al. Distribution and prognosis of uncommon metastases from non-small cell lung cancer. BMC Cancer. 2016;16:149.

2. Yeh KY, Chang JW, Hsueh S, Chang TC, Lin MC. Ovarian metastasis originating from bronchioloalveolar carcinoma: a rare presentation of lung cancer. Jpn J Clin Oncol. 2003;33(8):404-7.

3. Irving JA, Young RH. Lung carcinoma metastatic to the ovary: a clinicopathologic study of 32 cases emphasizing their morphologic spectrum and problems in differential diagnosis. Am J Surg Pathol. 2005;29(8):997-1006.

4. Timmerman D, Van Calster B, Testa A, et al. Predicting the risk of malignancy in adnexal masses based on the Simple Rules from the International Ovarian Tumor Analysis group. Am J Obstet Gynecol. 2016;214(4):424-37.

5. Fujiwara K, Ohishi Y, Koike H, Sawada S, Moriya T, Kohno I. Clinical implications of metastases to the ovary. Gynecol Oncol. 1995;59(1):124-8.

6. Kiyokawa T, Young RH, Scully RE. Krukenberg tumors of the ovary: a clinicopathologic analysis of 120 cases with emphasis on their variable pathologic manifestations. Am J Surg Pathol. 2006:30(3):277-99.

7. Bi R, Bai Q, Zhu X, et al. ALK rearrangement: a high-frequency alteration in ovarian metastasis from lung adenocarcinoma. Diagn Pathol. 2019;14(1):96
8. Jing X, Li F, Meng X, Liu Z, Yu J, Liu B. Ovarian metastasis from lung adenocarcinoma with ALK-positive rearrangement detected by next generation sequencing: a case report and literatures review. Cancer Biol Ther. 2017;18(5):279-84.

9. Mushi RT, Yang Y, Cai Q, Zhang R, Wu G, Dong X. Ovarian metastasis from non-small cell lung cancer with ALK and EGFR mutations: a report of two cases. Oncol Lett. 2016;12(6):4361-6.

10. Fujiwara A, Higashiyama M, Kanou T, et al. Bilateral ovarian metastasis of non-small cell lung cancer with ALK rearrangement. Lung Cancer. 2014;83(2):302-4

11. West AH, Yamada SD, MacMahon $\mathrm{H}$, et al. Unique metastases of ALK mutated lung cancer activated to the adnexa of the uterus. Case Rep Clin Pathol. 2014;1(2):151-4.

12. Gow CH, Chang YL, Hsu YC, et al. Comparison of epidermal growth factor receptor mutations between primary and corresponding metastatic tumors in tyrosine kinase inhibitor-naive non-small-cell lung cancer. Ann Oncol. 2009;20(4):696-702.

13. Lionetti $R$, De Luca M, Travaglino A, et al. Treatments and overall survival in patients with Krukenberg tumor. Arch Gynecol Obstet. 2019;300(1):15-23.

\section{Publisher's Note}

Springer Nature remains neutral with regard to jurisdictional claims in published maps and institutional affiliations.
Ready to submit your research? Choose BMC and benefit from:

- fast, convenient online submission

- thorough peer review by experienced researchers in your field

- rapid publication on acceptance

- support for research data, including large and complex data types

- gold Open Access which fosters wider collaboration and increased citations

- maximum visibility for your research: over $100 \mathrm{M}$ website views per year

At BMC, research is always in progress.

Learn more biomedcentral.com/submissions 